Cite this: RSC Adv., 2014, 4, 8317

Received 13th September 2013 Accepted 27th November 2013

DOI: $10.1039 / c 3 r a 45095 c$

www.rsc.org/advances

\title{
Revoking excited state intra-molecular hydrogen transfer by size dependent tailor-made hierarchically ordered nanocapsules
}

\author{
Mai Mouslmani and Digambara Patra*
}

\begin{abstract}
Curcumin associated poly(allylamine hydrochloride) cross-links with dipotassium phosphate and subsequently is assembled with $\sim 24 \mathrm{~nm}$ $\mathrm{SiO}_{2}$ nanoparticles to form hierarchically ordered nanocapsule structures, which are 100-1000 $\mathrm{nm}$ in size depending on the concentration of dipotassium phosphate. These structures reverse the excited state intra-molecular hydrogen transfer in curcumin depending on the size of the nanocapsules.
\end{abstract}

Excited state hydrogen transfer has sparked the curiosity to understand the intrinsic mechanisms involved in chemical and biological processes. ${ }^{1-4}$ Excited State Intra-molecular Hydrogen Transfer (ESIHT) occurs on a unimolecular basis and serves as a model to mimic catalytic reactivity. ${ }^{5}$ ESIHT has been associated with medicinal properties. ${ }^{6}$ At the same time, in material research fluorescence switching of chromophores has drawn intense excitement because of its desirable physicochemical behaviour for sensing and imaging applications. ${ }^{7}$ Curcumin $(\mathrm{CU})^{8}$ is proven to have antioxidant, anti-inflammatory, anticancer, anti-amyloid, anti-HIV, anti-microbial, etc. properties and its antioxidant mechanism has been linked with $\mathrm{H}$-atom transfer. ${ }^{6} \mathrm{CU}$ is found to exist in enolic form and undergoes ESIHT during the deactivation process. ${ }^{9-18}$ Thus, understanding ESIHT of CU sheds light on its medicinal values. Although normal $\left(\mathrm{N}^{*}\right)$ and ESIHT ( $\left.\mathrm{E}^{*}\right)$ forms can be simultaneously observed for many organic molecules in steady state spectra, no steady state emission spectrum from the normal form of $\mathrm{CU}\left(\mathrm{N}^{*}\right)$ has been simultaneously detected in solution or solid state, despite the indication of an ESIHT phenomenon in CU by ultra-fast timeresolved spectra and fluorescence up-conversion data, ${ }^{10-12}$ which is further supported by theoretical calculations. ${ }^{\text {14-18 }}$

With the objective of revoking the ESIHT deactivation process of a model molecule, CU, we apply nanotechnology ${ }^{19-22}$ to prepare new materials which have unique optical properties that can be controlled with the size dependency of

Department of Chemistry, American University of Beirut, Beirut, Lebanon. E-mail: dp03@aub.edu.lb; Fax: +9611365 217; Tel: +961 1350000 ext. 3985 nanocapsules (NCs). Structurally well-defined architectures with dynamic and stimulus responsive properties have been designed and have been among important trials. ${ }^{23-29} \mathrm{CU}$ was identified because of its (i) growing pharmaceutical relevance, (ii) use as a popular food spice and, (iii) exciting photophysical properties. Moreover, CU meets our present goal as the emission from only the $\mathrm{E}^{*}$ form is detected and the emission from the $\mathrm{N}^{*}$ form is completely masked/undetected in solution as shown in steady state fluorescence spectra. In this study, NCs were prepared by mixing $1.3 \mathrm{~mL}$ of $3 \mathrm{mg} \mathrm{mL} \mathrm{mL}^{-1}$ poly(allylamine hydrochloride), $\mathrm{PAH}$, with $0.5 \mathrm{~mL}$ of $1 \mathrm{mg} \mathrm{mL} \mathrm{mL}^{-1} \mathrm{CU}$. The interaction of $\mathrm{CU}$ with $\mathrm{PAH}$ was found to be strong due to the electrostatic and hydrophobic interactions between them.

The self-assembly of the mixture was achieved by crosslinking the CU-PAH chains with $7.8 \mathrm{~mL}$ of $2.5 \mathrm{mM}$ dipotassium phosphate in aqueous media at $\mathrm{pH} 4.4$ for 30 minutes. Afterwards $7.8 \mathrm{~mL}$ of a $40 \mathrm{wt} \%$ suspension of $\sim 24 \mathrm{~nm}$ silica nanoparticles $\left(\mathrm{SiO}_{2} \mathrm{NPs}\right)$ at $\mathrm{pH} \sim 9.8$ was added to this aggregated solution. It should be noted that the $\mathrm{pH}$ of the colloid solution increased to 9.5 while adding the silica sol. The cloudy solution was kept for $2 \mathrm{~h}$. The solution was centrifuged and washed three times in deionized water and then dispersed in $3 \mathrm{~mL}$ of water for further characterization and investigation. Due to their overall net positive charge these aggregates of CU-PAH-dipotassium phosphate could assist the assembly of negatively charged silica nanoparticles, which then shape into hierarchically ordered nanocapsule structures ${ }^{\mathbf{1 9}}$ as illustrated in Scheme 1. The SEM images, depicted in Fig. 1A, show that the NCs are spherical. The SEM image of the CU-PAH-dipotassium phosphate mixture, before silica nanoparticles were added, is shown in the inset of Fig. 1A, which suggests that smaller size spherical aggregates are formed before the silica nanoparticles are added. The particle size distribution of the nanocapsules was analyzed by a dynamic light scattering (DLS) method and was found to have an effective hydrodynamic radius $\left(R_{\mathrm{h}}\right)$ of $480 \mathrm{~nm}$ for 2.5 $\mathrm{mM}$ of dipotassium phosphate. The hydrodynamic diameter size distribution was found to be $0.2-1 \mu \mathrm{m}$. Increasing the concentration of dipotassium phosphate to $5 \mathrm{mM}$ increased the 

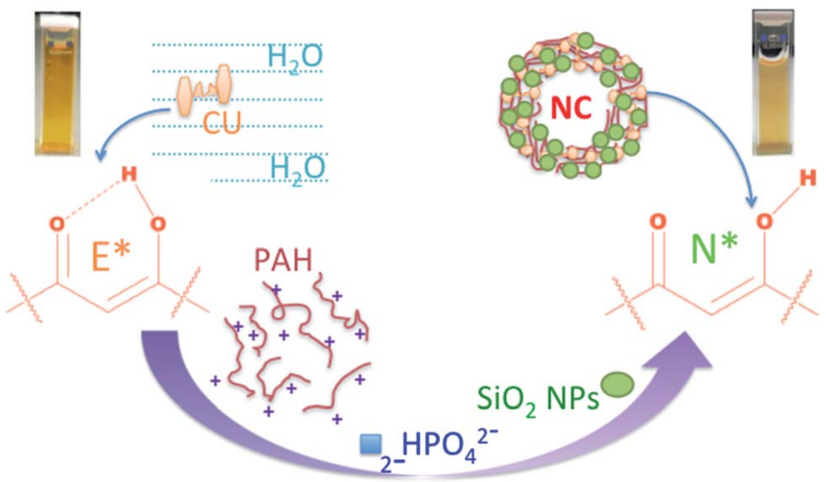

Scheme 1 Illustration of $\mathrm{CU}$ interacting with $\mathrm{PAH}$, dipotassium phosphate and $\mathrm{SiO}_{2} \mathrm{NPs}$ to form NCs that revoke the ESIHT process of $\mathrm{CU}$ and introduce a normal emitting pathway.
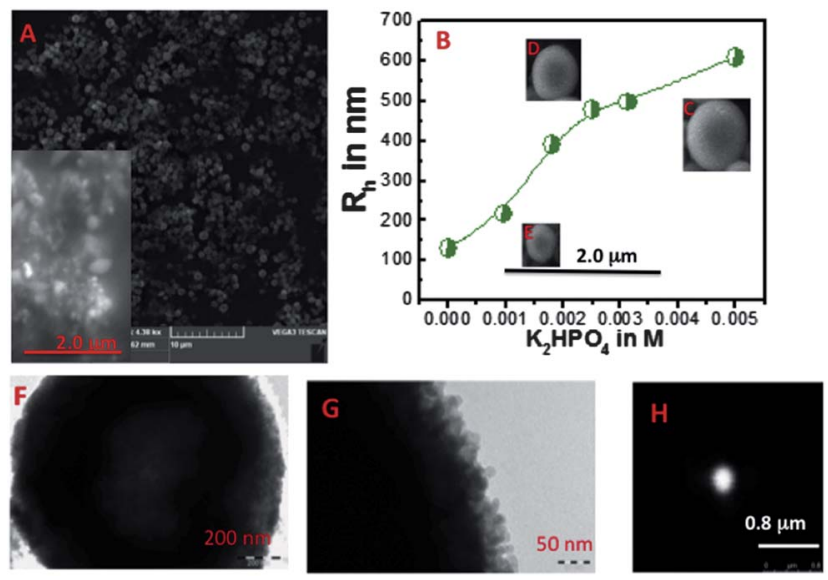

Fig. 1 (A) SEM images of NCs, the inset shows a SEM image of the CU$\mathrm{PAH}$-dipotassium phosphate mixture before $\mathrm{SiO}_{2} \mathrm{NPs}$ were added; (B) plot of the hydrodynamic radius $\left(R_{h}\right)$ vs. the concentration of dipotassium phosphate; (C) - (E) show the corresponding SEM images; (F) and $(G)$ TEM images and $(H)$ STED confocal fluorescence image of NCs. F-H show particles from the same batch.

$R_{\mathrm{h}}$ value to $610 \mathrm{~nm}$, similarly decreasing the salt concentration to $10 \mu \mathrm{M}$ produced NCs with a $R_{\mathrm{h}}$ of $133 \mathrm{~nm}$ (see Fig. 1B-E). However, the SEM images show that the NCs were found to be much smaller $\left(R_{\mathrm{h}}=\sim 60 \mathrm{~nm}\right)$ at the low salt concentration. The high effective hydrodynamic radius is due to the further aggregation of smaller size NCs in solution. The increase in the concentration of dipotassium phosphate increases the negative charges of the salt per positive charge of $\mathrm{PAH}$, which encourages the formation of larger aggregates, thus, increasing the size of the core as well as the hydrodynamic radius of the NC. ${ }^{20}$ Such an aggregation was also noticed when NCs were prepared in solution and dried on a carbon adhesive before taking the SEM images. The TEM image, Fig. 1F, of NCs confirms that the silica particles are at the surface and the material at the center is thinner. The thickness of silica was about 100-250 nm (Fig. 1G). The fluorescence image, Fig. $1 \mathrm{H}$, indicates that the fluorescence is coming from all over the capsules suggesting that $\mathrm{CU}$ is present all over the capsules. As CU is strongly and ionically bound to $\mathrm{PAH}$, we expect that $\mathrm{CU}$ will be present along with $\mathrm{PAH}$. This result also established that NCs are core-shell structures instead of being hollow in nature.

The absorption spectrum of the NCs was found to be similar to that of CU (see Fig. 2A), however, the $\mathrm{S}_{0} \rightarrow \mathrm{S}_{2}$ transition of CU at $\sim 266 \mathrm{~nm}$ was not well resolved in the NCs. The $\beta$-diketone moiety of CU exists entirely in enol form with a trans-geometry in both solid state ${ }^{30}$ and solution, ${ }^{8}$ thereby getting two feruloyl chromophores to interact with each other via a central $\mathrm{sp}^{2}$ hybridised carbon atom in a common conjugated $\pi$-system. ${ }^{31,32}$ The strong $\pi($ HOMO $) \rightarrow \pi($ LUMO $)$ transition of CU was found to be $426 \mathrm{~nm}$ in a buffer solution that masked the weak electronic dipole forbidden $\mathrm{n} \rightarrow \pi$ band. This band is in agreement with the theoretically predicted value for $\mathrm{CU}$ in the enol form. ${ }^{14-18}$ Interestingly, the excitation spectrum of $\mathrm{CU}$ in the buffer solution shows two excitation wavelength bands at $\sim 368$ $\mathrm{nm}$ and $\sim 445 \mathrm{~nm}$ (Fig. 2B), unlike the absorption spectrum, which clearly suggests that the absorbing and emitting species for CU are different. The first excited state of $\mathrm{CU}$ is highly polar due to the intramolecular charge transfer from the phenyl ring towards the carbonyl moiety ${ }^{\mathbf{9} 31,32}$ and ESIHT is a major photophysical process in the deactivation of the excited state of CU. ${ }^{9-13}$ The absorption shoulder at $\sim 370 \mathrm{~nm}$ is due to the weakly allowed $\pi(\mathrm{HOMO}-1) \rightarrow \pi($ LUMO $)$ transition and/or the virtually forbidden $\mathrm{n} \rightarrow \pi$ (LUMO) transition. ${ }^{16}$ The emission spectrum obtained for CU in water, while having excitation bands at $355 \mathrm{~nm}, 427 \mathrm{~nm}$ and $450 \mathrm{~nm}$, was similar with a maximum at $\sim 552 \mathrm{~nm}$ (for $\lambda_{\text {ex }}=355 \mathrm{~nm}$ ) and a maximum at $555 \mathrm{~nm}$ (for $\lambda_{\text {ex }}=427$ and $450 \mathrm{~nm}$ ) without any emitting band at $\sim 450 \mathrm{~nm}$ for $\mathrm{N}^{*}$, thus, the variation in the excitation spectrum of $\mathrm{CU}$ is due to ESIHT, since an unusually longer wavelength emission of $\mathrm{CU}$ in solution has been found to be due to ESIHT. ${ }^{9-18}$ However,
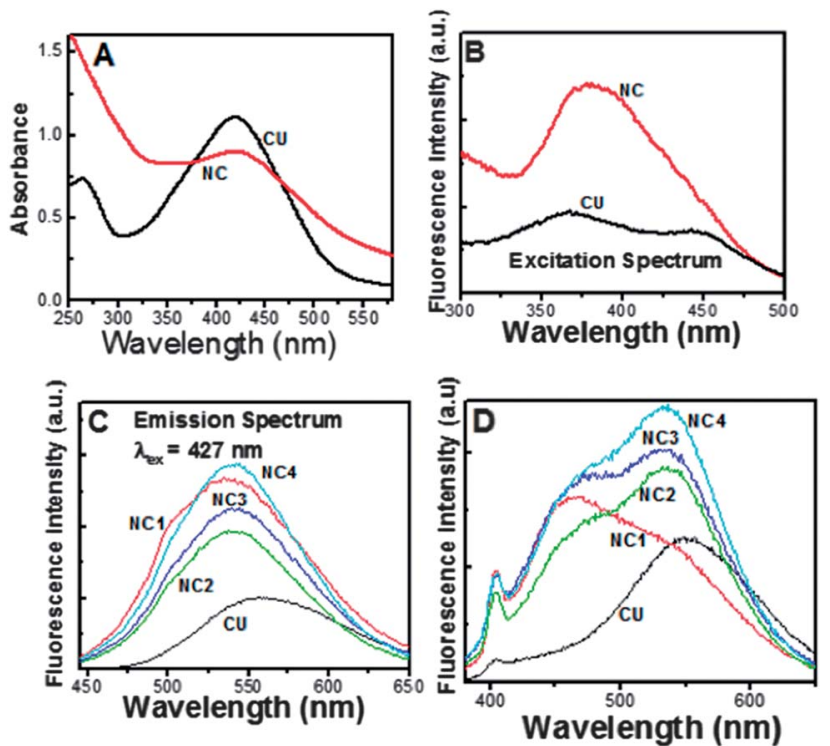

Fig. 2 UV-Visible absorption spectra (A), fluorescence excitation spectra at $\lambda_{\mathrm{em}}=427 \mathrm{~nm}$ (B), fluorescence emission spectra at $\lambda_{\mathrm{ex}}=$ $427 \mathrm{~nm}(C)$, and fluorescence emission spectra at $\lambda_{\mathrm{ex}}=355 \mathrm{~nm}$ (D) for $\mathrm{CU}$ in buffer and NCs in water. 
the excitation spectrum of NCs showed a completely different behavior compared to $\mathrm{CU}$ in water, despite the fact that both $\mathrm{CU}$ and NCs have a similar strong $\pi(\mathrm{HOMO}) \rightarrow \tau(\mathrm{LUMO})$ transition absorption (Fig. 2A) at $427 \mathrm{~nm}$. In the NCs, the excitation maximum was $\sim 50 \mathrm{~nm}$ blue shifted compared to the strong $\pi($ HOMO $) \rightarrow \pi$ (LUMO) transition absorption band, thus, the weakly allowed $\pi(\mathrm{HOMO}-1) \rightarrow \pi(\mathrm{LUMO})$ transition and the virtually forbidden $n \rightarrow \pi($ LUMO) transition play a vital role during the fluorescence process in NCs. The emission spectra for NCs at $\lambda_{\mathrm{ex}}=427 \mathrm{~nm}$ (Fig. 2C) and $450 \mathrm{~nm}$ were similar with a maximum centered at $\sim 540 \mathrm{~nm}$, the $\sim 10 \mathrm{~nm}$ blue shift of emission maximum of NCs compared to $\mathrm{CU}$ in water at these excitation wavelengths is due to the change in local environment and solvent. ${ }^{., 33-35}$ However, the emission spectrum for NCs obtained at $\lambda_{\mathrm{ex}}=355 \mathrm{~nm}$ (Fig. 2D) is largely different with a maximum at $\sim 536 \mathrm{~nm}$ and an additional new peak at a lower wavelength. The deconvolution of this spectrum gave two separate emission spectra centered at $\sim 456 \mathrm{~nm}$ and $\sim 535 \mathrm{~nm}$ (see Fig. 3A). The additional peak observed is not due to the change in the solvent of the NCs but due to the fact that even at $\lambda_{\text {ex }}=427 \mathrm{~nm} \mathrm{CU}$ alone gives a much larger blue shift $(\sim 80 \mathrm{~nm})$ in a non-polar solvent environment, ${ }^{33}$ however, in the present case of $\lambda_{\mathrm{ex}}=427 \mathrm{~nm}$, the blue shift in emission spectrum was only $15 \mathrm{~nm}$ for the NCs (Fig. 2C) instead of the $\sim 80 \mathrm{~nm}$ expected for a non-polar solvent environment. Therefore, a $10 \mathrm{~nm}$ shift (from $550 \mathrm{~nm}$ in water to $540 \mathrm{~nm}$ in NCs) at $\lambda_{\mathrm{ex}}=355 \mathrm{~nm}$ is due to the change in solvent for the NCs whereas the additional peak at $\sim 456 \mathrm{~nm}$ is due to other phenomena as explained subsequently.

In the steady state fluorescence spectrum in water or alcohol, the band at $\sim 456 \mathrm{~nm}$ was never resolved. However, using an ultrafast time resolved spectroscopic method the normal emission spectrum $\left(\mathrm{N}^{*}\right)$ of $\mathrm{CU}$ in methanol at a 0 picosecond

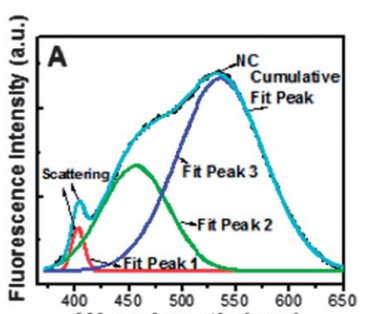

Wavelength $(\mathrm{nm})$
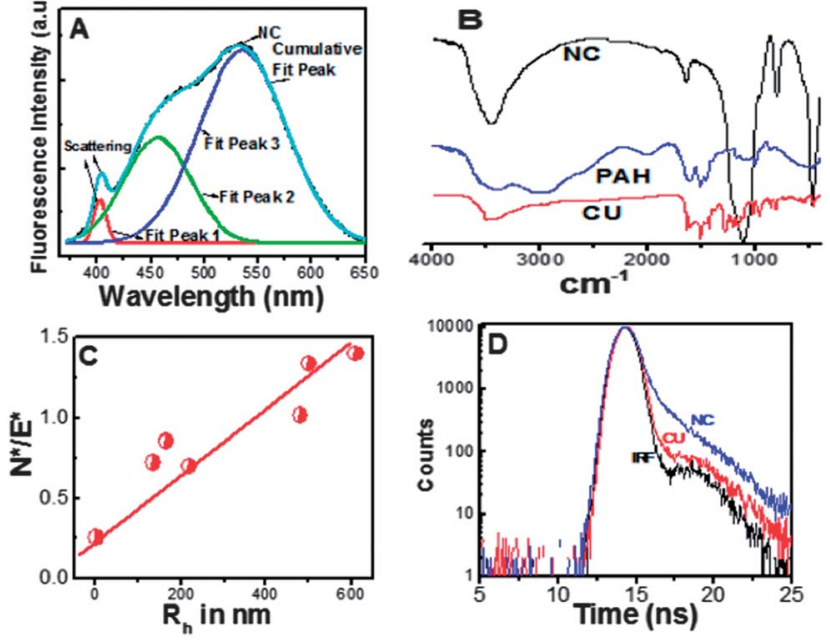

Fig. 3 (A) Fluorescence emission spectrum of the NCs at $\lambda_{\mathrm{ex}}=355 \mathrm{~nm}$ along with deconvoluted spectra, the peak at $\sim 400 \mathrm{~nm}$ is due to scattering; (B) FT-IR spectra of $\mathrm{CU}, \mathrm{PAH}$ and $\mathrm{NC}$; (C) plot of $\mathrm{N} / \mathrm{E} * v s$. $R_{\mathrm{h}}$ of NCs; (D) fluorescence lifetime decay profiles for CU and NCs at $\lambda_{\mathrm{ex}}=460 \mathrm{~nm}$ and $\lambda_{\mathrm{em}}=560 \mathrm{~nm}$, IRF is the instrument response function. (ps) time scale has been resolved with a maximum at $\sim 460 \mathrm{~nm}$, whereas the emission spectrum of the ESIHT ( $\mathrm{E}^{*}$ ) form at more than $20 \mathrm{ps}$ is centered at $\sim 555 \mathrm{~nm}$ and resembles the steady state fluorescence spectrum. ${ }^{\mathbf{1 0}}$ It should be noted that there is no remarkable emission band at $\sim 465 \mathrm{~nm}$ for $\mathrm{CU}$ in methanol at $\lambda_{\mathrm{ex}}=355 \mathrm{~nm}$ (ref. 9) indicating that the weakly allowed $\pi($ HOMO-1) $\rightarrow \pi($ LUMO $)$ transition and the virtually forbidden $\mathrm{n} \rightarrow \pi$ (LUMO) transition play insignificant roles during the steady state fluorescence process of $\mathrm{CU}$ in solution. Thus, the observed emission at $\sim 456 \mathrm{~nm}$ in NCs is because of the molecular deactivation without undergoing ESIHT. We further propose that the six membered ring path of the ESIHT deactivation process (see Scheme 2) is hindered due to the interaction of $\mathrm{N}^{+}$of $\mathrm{PAH}$ with the $\mathrm{O}$-atoms of the enol form of CU. FT-IR spectral data (Fig. 3B) further support our hypothesis. The phenolic O-H vibration of CU was observed at $\sim 3509 \mathrm{~cm}^{-1}$ and $3400 \mathrm{~cm}^{-1}$ whereas the peaks found in the range $3392-3033$ $\mathrm{cm}^{-1}$ in $\mathrm{PAH}$ are associated with the $\mathrm{N}-\mathrm{H}$ stretch. All these prominent peaks in the control samples were not visible in the NCs, instead a major peak was found at $3448 \mathrm{~cm}^{-1}$. Similarly a peak at $2972 \mathrm{~cm}^{-1}$ due to enolic $\mathrm{O}-\mathrm{H}$ vibration could be detected in CU, but was not clear in the NCs. Further, the control peaks at $1627 \mathrm{~cm}^{-1}$ and $1603 \mathrm{~cm}^{-1}$ for $\mathrm{CU}$ are associated with the $\mathrm{C}=\mathrm{O}$ and $\mathrm{C}=\mathrm{C}$ vibrations. The $\mathrm{C}=\mathrm{O}$ vibration has another peak at $1510 \mathrm{~cm}^{-1}$. On the other hand for PAH, the peaks at $1608 \mathrm{~cm}^{-1}$ and $1457 \mathrm{~cm}^{-1}$ are associated with the $\mathrm{N}-\mathrm{H}$ asymmetric bending and $\mathrm{C}-\mathrm{H}$ bending. In the NCs the only prominent peak was obtained at $1636 \mathrm{~cm}^{-1}$ in these regions, confirming strong interactions from $-\mathrm{NH}_{2}$ of $\mathrm{PAH}$ and enol of CU inside the NC.

The ratio of $\mathrm{N}^{*} / \mathrm{E}^{*}$ was evaluated by measuring the fluorescence ratio at $460 \mathrm{~nm}$ (normal emission) and at $540 \mathrm{~nm}$ (ESIHT emission). $\mathrm{N}^{*} / \mathrm{E}^{*}$ was found to be 0.25 for $\mathrm{CU}$ in water, which increased 3 fold in NCs. Further, $\mathrm{N}^{*} / \mathrm{E}^{*}$ enhanced with the increase in NC size as shown in Fig. 3C. The maximum value was found for the NCs having the largest size and $\mathrm{N}^{*} / \mathrm{E}^{*}$ could be linearly correlated with the hydrodynamic radius of the NCs. The fluorescence lifetime at $\lambda_{\text {ex }}=460 \mathrm{~nm}$ and $\lambda_{\text {em }}=560 \mathrm{~nm}$ for CU in buffer could be best fitted with a biexponential decay giving a short component lifetime $\left(\tau_{1}\right)$ of $\sim 62$ ps $(99 \%)$ and a long component lifetime $\left(\tau_{2}\right)$ of $3.1 \mathrm{~ns}(1 \%)$. The biexponential decay for NCs at these excitation and emission wavelengths

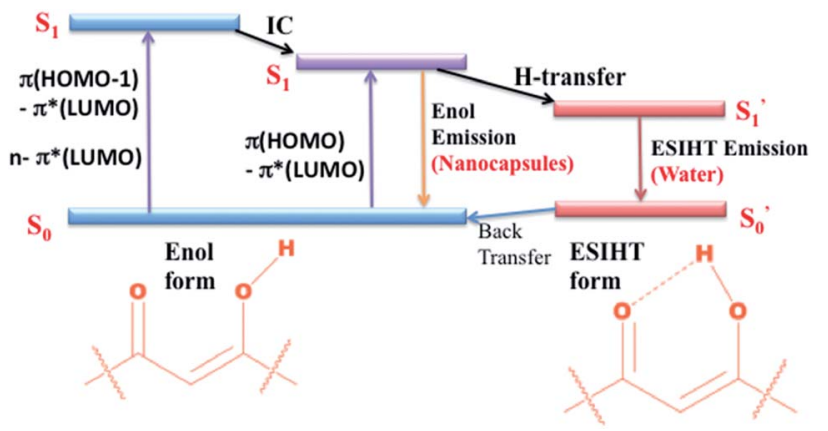

Scheme 2 Absorption and excited state deactivation processes of $\mathrm{CU}$ in water and NCs. 
provided $\tau_{1}=\sim 242 \mathrm{ps}(80 \%)$ and $\tau_{2}=1.90 \mathrm{~ns}(20 \%)$ when $R_{\mathrm{h}}=$ $133 \mathrm{~nm}$. The decay profiles are shown in Fig. 3D. The increase in the size of NCs decreased $\tau_{1}$ to 178 ps (85\%) but increased $\tau_{2}$ to $3.00 \mathrm{~ns}(15 \%)$ when $R_{\mathrm{h}}=610 \mathrm{~nm}$. The decrease in $\tau_{2}$ correlated with the increase in the size of NCs, thus, could be rationalised with the decrease in the ESIHT process in the NCs. However, while exciting at $373 \mathrm{~nm}$ the biexponential decay of CU in buffer at emission $460 \mathrm{~nm}$ (for $\mathrm{N}^{*}$ ) gave $\tau_{1}=0.35 \mathrm{~ns}(90 \%)$ and $\tau_{2}=3.9$ ns $(10 \%)$ whereas the emission at $560 \mathrm{~nm}$ (for $\mathrm{E}^{*}$ ) gave $\tau_{1}=0.33$ ns $(90 \%)$ and $\tau_{2}=\sim 1.0 \mathrm{~ns}(10 \%)$. This emission wavelength dependency of CU is not surprising as a similar dependency in ethanol is known. ${ }^{36}$ At $\lambda_{\text {ex }}=373 \mathrm{~nm}$ and $\lambda_{\mathrm{em}}=460 \mathrm{~nm}$, the $\tau_{1}$ value dramatically improved to $0.40 \mathrm{~ns}$ in NCs and later on to $0.60 \mathrm{~ns}$ with the increase in $R_{\mathrm{h}}$ of NCs, therefore, the increase in $\tau_{1}$ could be logically related to the emission of $\mathrm{N}^{*}$.

In summary, $\mathrm{CU}$ in the presence of PAH and dipotassium phosphate directly assembles with silica nanoparticles into spherical NCs in the size range of 100-1000 $\mathrm{nm}$. The size of the NCs was tailored by varying salt concentration and the fluorescence was switched to understand the intrinsic mechanisms in chemical and biological processes. For example, revoking the ESIHT process of CU inside the NCs opens up a new emitting deactivation pathway that was never observed in water, thus, applying nanotechnology, optical behaviour could be tuned by tailor-made capsules for multiple applications in electronics, sensing and biomedical uses. At the same time the ESIHT phenomenon may help to understand the key fundamental questions of various $\mathrm{H}$-atom transfer pathways of medicinally important and water insoluble drug molecules, like CU, while using various capsules as a drug delivery system.

\section{Acknowledgements}

The financial support from the Lebanese National Council of Scientific Research (LNCSR) and American University of Beirut through URB and the long term faculty development grant are acknowledged.

\section{Notes and references}

1 T. Elsässer and H. J. Bakker, Ultrafast hydrogen bonding dynamics and proton transfer processes in the condensed phase, Kluwer Academic Publishers, Dordrecht, Boston, 2002.

2 T. J. Meyer, M. H. V. Huynh and H. H. Thorp, Angew. Chem., Int. Ed., 2007, 46, 5284.

3 S. Hammes-Schiffer, Chem. Rev., 2010, 110, 6937.

4 U. Pischel, D. Patra, A. L. Koner and W. M. Nau, Photochem. Photobiol., 2006, 82(1), 310.

5 A. P. Demchenko, K.-C. Tang and P.-T. Chou, Chem. Soc. Rev., 2013, 42, 1379.

6 S. V. Jovanovic, S. Steenken, C. W. Boone and M. G. Simic, J. Am. Chem. Soc., 1999, 121, 9677.
7 C. Yun, J. You, J. Kim, J. Huh and E. Kim, J. Photochem. Photobiol., C, 2009, 10, 111.

8 M. M. Yallapu, M. Jaggi and S. C. Chauhan, Drug Discovery Today, 2012, 17, 71.

9 S. M. Khopde, K. I. Priyadarsini, D. K. Palit and T. Mukherjee, Photochem. Photobiol., 2000, 72, 625.

10 R. Adhikari, P. Mukeerjee, T. W. Kee and J. W. Petrich, J. Phys. Chem. B, 2009, 113, 5255.

11 R. Adhikary, P. J. Carlson, T. W. Kee and J. W. Petrich, J. Phys. Chem. B, 2010, 114, 2997.

12 T. W. Kee, R. Adhikary, P. J. Carlson, P. Mukherjee and J. W. Petrich, Aust. J. Chem., 2011, 64, 23.

13 I. Presiado, Y. Erez, R. Gepshtein, N. Koifman and D. Huppert, J. Photochem. Photobiol., A, 2012, 247, 42.

14 L. Kong, K. I. Priyadarsini and H.-Y. Zhang, J. Mol. Struct., 2004, 684, 111.

15 C. R. Baiz and B. D. Dunietz, J. Phys. Chem. A, 2007, 111, 10139. 16 V. Galasso, B. Kovač, A. Modelli, M. F. Ottaviani and F. Pichierri, J. Phys. Chem. A, 2008, 112, 2331.

17 L. Shen, H.-Y. Zhang and H.-F. Ji, Org. Lett., 2005, 7, 243.

18 L. Shen and H.-F. Ji, Spectrochim. Acta, Part A, 2007, 67, 619.

19 D. Patra, A. J. Amali and R. K. Rana, J. Mater. Chem., 2009, 19, 4017.

20 R. K. Rana, V. S. Murthy, J. Yu and M. S. Wong, Adv. Mater., 2005, 17, 1145.

21 A. J. Amali, N. H. Awwad, R. K. Rana and D. Patra, Anal. Chim. Acta, 2011, 708, 75.

22 D. Patra, R. Aridi and K. Bouhadir, Microchim. Acta, 2013, $180,59$.

23 J. N. Anker, W. P. Hall, O. Lyandres, N. C. Shah, J. Zhao and R. P. Van Duyne, Nat. Mater., 2008, 7, 442.

24 S. Nayak and L. A. Lyon, Angew. Chem., Int. Ed., 2004, 43, 6706.

25 R. C. Bailey, J. M. Nam, C. A. Mirkin and J. T. Hupp, J. Am. Chem. Soc., 2003, 125, 13541.

26 P. M. Mendes, Chem. Soc. Rev., 2008, 37, 2512.

27 Z. S. Liu and P. Calvert, Adv. Mater., 2000, 12, 288.

28 D. Roy, J. N. Cambre and B. S. Sumerlin, Chem. Commun., 2009, 2106.

29 K. S. Soppimath, D. C. W. Tan and Y. Y. Yang, Adv. Mater., $2005,17,318$.

30 H. H. Tonnesen, J. Karlsen and A. Mostad, Acta Chem. Scand., Ser. B, 1982, 36, 475.

31 P. H. Bong, Bull. Korean Chem. Soc., 2000, 21, 81.

32 F. Zsila, Z. Bikádi and M. Simonyi, Tetrahedron: Asymmetry, 2003, 14, 2433.

33 D. Patra and C. Barakat, Spectrochim. Acta, Part A, 2011, 79, 1034.

34 D. Patra, E. E. Khoury, D. Ahmadieh, S. Darwish and R. M. Tafech, Photochem. Photobiol., 2012, 88, 317.

35 D. Patra, C. Barakat and R. M. Tafech, Colloids Surf., B, 2012, 94, 354.

36 Y. Erez, I. Presiado, R. Gepshtein and D. Huppert, J. Phys. Chem. A, 2011, 115, 10962. 